\title{
Lung Cancer pM1b TNM Finding v7
}

National Cancer Institute

\section{Source}

National Cancer Institute. Lung Cancer pM1b TNM Finding v7. NCI Thesaurus. Code C88881.

Distant metastasis. (from AJCC 7th Ed.) 